\title{
Aferição do grau de responsabilidade social empresarial em MPES de Jundiaí e Região
}

\section{Assessment of the degree of corporate social responsibility in MSCS in Jundiaí and Region}

\author{
WALTER LUIZ DE OLIVEIRA* \\ JOÃO EDUARDO PRUDÊNCIO TINOCO** \\ JOSÉ ALBERTO CARVALHO DOS SANTOS CLARO***
}

\section{RESUMO}

A adoção das estratégias de Responsabilidade Social Empresarial (RSE) possibilita às empresas prevenir e corrigir erros, aprimorar sua eficiência operacional, gerando economia, melhorando sua sustentabilidade e suas chances de sobrevivência. Diante disso, o objetivo geral desta pesquisa foi a aferição do grau de RSE de MPEs do Aglomerado Urbano de Jundiaí (AUJ), adotando-se o critério proposto pela obra "Indicadores Ethos-Sebrae de Responsabilidade Social Empresarial" (2013). Como metodologia, foi seguida a abordagem qualitativa, realizando-se pesquisa de campo com estudo de múltiplos casos (dezoito empresas da indústria, comércio e serviços), em que se utilizou o método de triangulação mediante questionário, entrevista semiestruturada e observações in loco. Como resultado, as empresas pesquisadas obtiveram 66,20 pontos percentuais, o que conferiu a elas o grau médio-alto de desempenho em RSE. No entanto, foram diagnosticadas dezessete deficiências de desempenho quanto a RSE, das

* Mestre em Administração de MPEs pela Faculdade Campo Limpo Paulista - FACCAMP. walterluizdeoliveira@gmail.com

** Doutor em Controladoria e Contabilidade pela Universidade de São Paulo; Pesquisador e Professor do Programa de Mestrado e Doutorado em Administração da Faculdade Campo Limpo Paulista - FACCAMP. joao.tinoco@faccamp.br

*** Universidade Federal de São Paulo - UNIFESP. Professor Adjunto Nível C1 de Administração, com Dedicação Exclusiva, na UNIFESP - Universidade Federal de São Paulo, no Campus Baixada Santista, IMar - Instituto do Mar. Doutorado em Comunicação Social pela Universidade Metodista de São Paulo (2002). albertoclaro@albertoclaro.pro.br. 
quais se destacam: informalidade excessiva, autocracia e falta de transparência, imprecisão e insuficiência de dados gerenciais, pagamento de propina, sonegação fiscal, confusão patrimonial, problemas de acessibilidade, limitações ao desenvolvimento profissional, à empregabilidade e ao acesso à informação, inexistência de práticas de educação e conscientização ambiental, desinteresse quanto à responsabilidade social e ao desenvolvimento dos fornecedores locais, isolacionismo, desinteresse pelo voluntariado e aversão por envolvimento em questões políticas e sociais. Em conclusão, foram sugeridas algumas medidas saneadoras e a realização de novas pesquisas, visando à melhor compreensão do fenômeno.

Palavras-chave: Responsabilidade Social Empresarial. Micro e Pequenas Empresas. Aglomerado Urbano de Jundiaí.

\section{Abstract}

The adoption of Corporate Social Responsibility (CSR) strategies enables companies to prevent and correct errors, improve their operational efficiency, generate savings, improve their operational efficiency, generate savings, improve their sustainability and their chances of survival. In view of this, the general objective of this research was to assess the CSR degree of MSEs of the Urban Agglomerate of Jundiaí (UAJ), adopting the criterion proposed by the book "Ethos-Sebrae Indicators of Corporate Social Responsibility" (2013). The specific objectives were the identification, analysis and comparison of the determinants of the results; To point out the positive and negative aspects and to suggest remedial measures of the observed deficiencies. As a methodology, a qualitative approach was adopted. Field research was carried out with a multiple case study (eighteen companies from industry, commerce and services), in which the triangulation method was adopted through a questionnaire, semi-structured interview and in loco observations. As a result, the companies surveyed obtained 66.20 percentage points, which gave them the medium-high degree of performance in CSR. However, seventeen performance deficiencies regarding CSR were diagnosed, such as: excessive informality, autocracy and lack of transparency, imprecision and insufficiency of management data, payment of bribes, tax evasion, asset confusion, accessibility problems, limitations to professional 
development, employability and access to information, lack of education and environmental awareness practices, lack of interest in social responsibility and the development of local suppliers, isolationism, lack of interest in volunteering and aversion to involvement in political and social issues. In conclusion, some sanitation measures and new researches were suggested, aiming at a better understanding of the phenomenon.

Palavras-chave: Corporate Social Responsibility. Micro and Small Enterprises. Urban Agglomerate of Jundiaí.

\section{INTRODUÇÃo}

A Responsabilidade Social Empresarial (RSE) é uma estratégia gerencial que consiste na aplicação de preceitos de natureza ética, econômica, social e ambiental, voltados para a sustentabilidade da organização em suas relações com clientes, colaboradores, fornecedores, concorrentes, acionistas, outros financiadores, governos e comunidades (CALDAS; TAMBOSI FILHO; VIEIRA, 2014; MATTIOLI; CASTRO; CLARO; VIEIRA; SPERS, 2015; TACHIZAWA, 2015). Essa estratégia "estimula as empresas a aprimorar sua eficiência operacional, prevenindo e corrigindo erros, salvaguardando o patrimônio empresarial, num contínuo processo em busca da sustentabilidade" (TINOCO; ROBLES, 2006, p. 1.078), o que "possibilita a redução dos índices de mortalidade observados entre as microempresas, especialmente as mais jovens" (ALMEIDA, 2007, p. 56).

Assim, esta pesquisa tenta solucionar a seguinte questão: qual é o grau de responsabilidade social das MPEs que atuam no Aglomerado Urbano de Jundiaí (UJ)?

A escolha desse Aglomerado se justifica por suas características geoeconômicas, que proporcionam às empresas da região uma vocação natural para atuar com RSE, buscando o desenvolvimento sustentável com a preservação do equilíbrio ecológico e da qualidade de vida de seus habitantes, o que lhes confere grande potencial de obter vantagem competitiva.

Isso se deve ao fato de que o AUJ localiza-se entre dois grandes centros econômicos (São Paulo e Campinas); possui sua intensa atividade econômica, principalmente em razão de seu parque industrial, 
que também o torna um grande atrativo para os setores de comércio e serviços; e tem, no seu entorno, duas grandes áreas de preservação ambiental (Serra do Japi e Serra dos Cristais) e grandes áreas de variada produção agrícola e de turismo rural (Circuito das Frutas).

Para atingir sua finalidade, a pesquisa tem como objetivo geral a aferição do grau de desempenho das MPEs que atuam no AUJ, e analisá-lo à luz dos critérios propostos pela obra Indicadores ETHOS-SEBRAE de Responsabilidade Social, composto por sete Diretrizes: Transparência e Governança; Público Interno; Meio Ambiente; Fornecedores; Consumidores e Clientes; Comunidade; Governo e Sociedade (ETHOS-SEBRAE, 2013).

Os objetivos específicos consistem na identificação e análise dos fatores determinantes de seu desempenho na pesquisa, sob cada uma das referidas Diretrizes; comparar as informações e os dados obtidos junto às empresas pesquisadas, por setor econômico, tempo de atuação, número de colaboradores e receita bruta anual; identificar a maior e a menor predominância das Sete Diretrizes de RSE em cada um desses agrupamentos; sugerir medidas saneadoras das deficiências eventualmente observadas.

Esta pesquisa encontra justificativa na necessidade da adoção de estratégias que reduzam os índices de mortalidade precoce das MPEs que, atualmente, correspondem a 23,4\% de MPEs encerradas sem chegar a dois anos de existência e 58\% antes de completar cinco anos (SEBRAE, 2016).

Este estudo encontra-se organizado em cinco seções: a segunda contém o referencial teórico deste trabalho, inicialmente abordando o sistema de aferição da RSE adotado nesta pesquisa, tecendo algumas considerações sobre as MPEs e seus índices de mortalidade, a relação existente entre responsabilidade social e a sustentabilidade das MPEs e informações acerca da Aglomeração Urbana onde se localizam as empresas alvo da pesquisa.

A terceira seção trata dos procedimentos metodológicos, descrevendo a metodologia adotada e suas limitações; a quarta seção apresenta os resultados e a discussão e a quinta seção contém as considerações finais do estudo e sugestões de novas pesquisas. 


\section{REFERENCIAL TEÓRICO}

A Responsabilidade Social Empresarial (RSE) pode ser compreendida como sendo um conjunto de ações voluntárias, pelas quais as empresas aplicam preceitos de natureza ética, econômica, social e ambiental, no contexto da sustentabilidade em suas relações com clientes, colaboradores, fornecedores, concorrentes, acionistas, outros financiadores, governos e comunidades, visando ao desenvolvimento de negócios sustentáveis, preservando recursos ambientais e culturais para gerações futuras, respeitando a diversidade e promovendo a redução das desigualdades sociais (TACHIZAWA, 2015; MATTIOLI; CASTRO; CLARO; VIEIRA; SPERS, 2015).

Estudiosos defendem a adoção dessa estratégia gerencial, justificando que ela possibilita a redução dos índices de mortalidade observados entre as microempresas, especialmente as mais jovens, sustentando que essa estratégia estimula as empresas a aprimorar sua eficiência operacional, prevenindo e corrigindo erros, salvaguardando o patrimônio empresarial, num contínuo processo em busca da sustentabilidade (TINOCO; ROBLES, 2006, p. 1.078), aprimorando sua capacidade de pensar e agir, em três dimensões igualmente importantes: econômica, social e ambiental, de um modo conjunto e equilibrado, sem predominância de uma sobre as outras, na gestão e no planejamento de longo prazo (ALMEIDA, 2007, p. 56).

As primeiras obras sobre Responsabilidade Social foram publicadas, segundo Bicalho (2003), nos Estados Unidos da América, no início do século XX, por Charles Eliot (1906), Arthur Hakley (1907) e John Clarck (1916), mas não receberam apoio naquela época, por serem consideradas de cunho socialista.

A mesma autora informa que o tema só foi retomado em 1953, com a publicação do livro Social Responsabilities of the Businessman, de Howard Bowen, mas somente a partir da década de 1970, com o surgimento das organizações American Accouting Association e American Institute of Certified Public Accountants, que o tema Responsabilidade Social foi deixando de ser simples curiosidade e se transformou num novo campo de estudo, por se revelar um fator decisivo para o desenvolvimento e crescimento das empresas.

Assim, a importância do conjunto de valores e conceitos que são sintetizados na expressão "Responsabilidade Social Empre- 
sarial" (RSE) surgiu, segundo Tachizawa, "da percepção coletiva, em meados do século passado, de que a destruição e o consumo desenfreado dos recursos naturais, decorrentes do nosso estilo de vida, não é compatível com a finitude desses recursos" $(2015$, p. 8).

Nessa conjuntura, tem crescido a "mobilização da sociedade com ética, cidadania, desenvolvimento sustentável e inclusão social, tornando-se cada vez maior a pressão da sociedade para que as empresas atuem com responsabilidade social"' (ABNT 16001:2004).

Assim, ser mais responsável socialmente tornou-se fator de competitividade, conforme (MELLO, 2004), que no seu entendimento, quanto maior a responsabilidade social da empresa, tanto maior é o seu diferencial de qualidade com relação às demais organizações e, em busca dessa finalidade, necessário se torna que a empresa adote algum mecanismo de controle e aferição destinado à demonstração de seus atributos de RSE.

Tendo em vista tratar-se de pesquisa voltada para as micro e pequenas empresas, convém ressaltar que, no Brasil, elas são regidas pela Lei Complementar nํ. 123, de 14.12.2006, que teve sua redação alterada pela LC 155/2016, e regulamentação do Decreto $\mathrm{n}^{\circ}$. 8.538, de 06.10.2015), estabelece normas gerais relativas ao tratamento diferenciado e favorecido a ser dispensado às mesmas, especialmente no que se refere à apuração e recolhimento dos impostos e contribuições mediante regime único de arrecadação ("Simples Nacional"); obrigações trabalhistas e previdenciárias; acesso a crédito e ao mercado, inclusive quanto à preferência nas aquisições de bens e serviços pelos Poderes Públicos, à tecnologia, ao associativismo e às regras de inclusão.

Para obter o enquadramento legal e fazer jus aos incentivos fiscais e demais benefícios assegurados pela LC 123/06, as empresas devem obedecer ao critério estabelecido pelo Artigo 3ํ․, incisos I e II, com redação alterada pela LC 155/16, que toma por base a receita bruta auferida em cada ano-calendário, sendo consideradas microempresas aquelas com renda igual ou inferior a $\mathrm{R} \$ 360.000,00$ e empresa de pequeno porte aquela com renda superior a esse valor e igual ou inferior a $R \$ 4.800 .000,00$.

O estudo da RSE nas micro e pequenas empresas (MPEs) é especialmente importante, porque no Brasil “as MPEs correspondem 
a 99\% das empresas privadas, de um total de 6,4 milhões de estabelecimentos, de ostentarem $27 \%$ de participação no PIB nacional e responderem por $52 \%$ dos postos de trabalho do setor privado $(16,1$ milhões)", o que configura uma situação paradoxal, ante a elevada taxa de mortalidade que elas enfrentam, da ordem de " $23,4 \%$ de MPEs encerradas sem chegar a dois anos de existência e 58\% antes de completar cinco anos" (SEBRAE, 2016).

Essa taxa de mortalidade é atribuída a deficiências de planejamento e baixa capacitação em empreendedorismo (SEBRAE, 2016), relacionadas a fatores que, de tão disseminados nas MPEs brasileiras, são elencados pelo IBGE como algumas de suas principais características, como: das MPEs brasileiras, esses descritos, muitos dos fatores que contribuem para essa elevada taxa de mortalidade, são relatados pelo IBGE como algumas das principais características das MPES:

“(...) poder decisório centralizado; estreito vínculo entre os proprietários e as empresas, não se distinguindo, principalmente em termos contábeis e financeiros, pessoa física e jurídica; registros contábeis pouco adequados; (...) utilização de mão-de-obra não qualificada ou semiqualificada; baixo investimento em inovação tecnológica; maior dificuldade de acesso ao financiamento de capital de giro; relação de complementaridade e subordinação com as empresas de grande porte" (IBGE, 2013, p. 18).

Por sua vez, na medida em que as MPE passarem a adotar as práticas de RSE, “terão uma gestão mais consciente, com maior clareza sobre suas finalidades, melhor ambiente de trabalho, maior comprometimento de seus funcionários, relações mais conscientes com seus fornecedores, clientes mais satisfeitos e melhor reputação junto à comunidade, tornando-se agentes transformadores da sociedade" (ETHOS, 2003).

Levando-se em consideração que o âmbito de aplicação deste estudo é a Aglomeração Urbana de Jundiaí, convém explicar que se trata de uma Unidade Regional do Estado de São Paulo, localizada na capital e Campinas, estabelecida por força da Lei Complementar no. 1.146, de 24.08.2011 (SÃO PAULO, 2011), também é conhecida 
como "Aglomerado Urbano de Jundiaí" (FANELLI; SANTOS JR., 2013), que reúne os municípios de Jundiaí, Cabreúva, Campo Limpo Paulista, Itupeva, Jarinu, Louveira e Várzea Paulista, que possuem 13.590 estabelecimentos empresariais: 2.841 indústrias, 6.140 estabelecimentos comerciais e 4.939 de serviços.

Por sua relevância econômica, a AUJ tem sido objeto de pesquisas relativas à RSE, muitas das quais voltadas para as MPEs, como:

- Gestão ambiental e responsabilidade social: Tachizawa e Pozo (2007) apontaram baixos índices de RSE, constatando que $34,2 \%$ das MPEs ainda não adotam, ou simplesmente não comunicam suas políticas de gestão com pessoas ao seu público interno; $37,1 \%$ demonstraram ética no relacionamento com o poder público e $29,3 \%$ apontaram ética no relacionamento com fornecedores e clientes.

- Uso da Tecnologia da Informação nas MPEs: Sacilotti (2011) apontou atavismo dos gestores, ao constatar que eles, apesar de perceberem a importância da TI, ainda se faz necessário tornar os processos mais eficientes, com investimento em treinamento dos funcionários, incentivando-os a utilizar e extrair o máximo da tecnologia aplicada. A autora também apontou a paradoxal situação das MPEs do setor de comércio, por serem as que menos utilizam a TI, mas são as que possuem o maior grau de dependência em relação à informática.

- Estruturas e competências organizacionais: Picchiai (2013) verificou que os micro e pequenos empresários da região atuam de modo atávico e autocrático; possuem reduzido desenvolvimento de competências gerenciais e limitado conceito de gestão; não conseguem perceber com clareza os alcances e limites entre os conceitos e suas aplicações.

- Responsabilidade Social Ambiental das indústrias de Campo Limpo Paulista: Mello e Tachizawa (2015) constataram que, das empresas pesquisadas, somente metade possuía Sistemas de Qualidade com certificação ISO; apenas 1/3 apenas delas atuavam com responsabilidade social na gestão do capital humano; e somente 1/5 delas realizava contabilida- 
de ambiental, chegando à conclusão de que a maioria das indústrias de Campo Limpo Paulista não pode se classificar como socialmente responsáveis.

Destarte, à luz do contexto geoeconômico e organizacional em que foram realizados os estudos anteriores, percebe-se que a presente pesquisa poderá ser útil para estabelecer se o microempresariado local conseguiu elevar seu grau de proficiência em responsabilidade social.

Entre os padrões disponíveis para a aferição da RSE, esta pesquisa adotou os Indicadores Ethos-Sebrae de Responsabilidade Social (ETHOS-SEBRAE, 2013), por serem inteiramente voltados para a realidade social, econômica e cultural das micro e pequenas empresas brasileiras, melhor explicitado na Seção 3 (Procedimentos Metodológicos).

\section{Procedimentos Metodológicos}

Quanto à classificação desta pesquisa, adotou-se o critério proposto por Silva e Menezes (2005, p. 20), segundo os quais as pesquisas podem ser classificadas por meio de quatro critérios: pela sua natureza; pela forma de abordagem do problema; pelos objetivos e pelos procedimentos técnicos, adiante explicitados.

Do ponto de vista de sua natureza, trata-se de pesquisa aplicada, considerando-se que está direcionada para a obtenção de conhecimento com vistas à aplicação prática e à solução de problemas específicos.

Quanto aos objetivos, a pesquisa é descritiva, uma vez que com base na análise das informações obtidas, buscou-se aferir o grau de atuação das MPEs entrevistadas quanto à RSE e a compreensão dos fatores que contribuem para o seu maior ou menor desempenho relativo ao tema da pesquisa.

Quanto ao procedimento técnico, é uma pesquisa de campo para estudo de casos múltiplos, realizada mediante questionário com perguntas fechadas; entrevistas face a face, semiestruturadas, com questões abertas e observações do pesquisador.

Por fim, no que concerne à abordagem do problema, assume-se abordagem qualitativa (VIEIRA; RIVERA, 2012), com destaque para o método de triangulação que, segundo Flick (2013, p. 362), consiste 
numa "alternativa qualitativa que reúne dados qualitativos e quantitativos, utiliza múltiplos métodos de pesquisa, obtendo dados de distintos modos, fontes, locais e ambientes, assegurando a compreensão mais profunda do fenômeno investigado, permitindo assim que o fenômeno em estudo seja abordado de diferentes formas".

Para a obtenção dos dados, foi realizada pesquisa bibliográfica e entrevistas com os gestores das empresas pesquisadas, adotando-se as técnicas de questionário (36 questões fechadas, com cinco alternativas de respostas), entrevista semiestruturada ("interrogatório interativo", segundo Azevedo et al., 2013, p. 10) e observação in loco feita pelo pesquisador ("para identificar discrepâncias, incongruências e contradições entre dados", conforme proposto por Cresswell e Plano Clark, 2013, p. 73).

O questionário utilizado foi aquele proposto na obra "Indicadores Ethos-Sebrae de Responsabilidade Social" (ETHOS-SEBRAE, 2013), segundo o qual as empresas devem ser analisadas sob sete temas-diretrizes (ETHOS-SEBRAE, 2003), a serem evidenciados por meio de 36 indicadores e respectivas questões, conforme explicitado no Quadro 1:

\begin{tabular}{|c|c|c|c|}
\hline TEMA & DIRETRIZ & INDICADORES & QUESTÕES \\
\hline $\begin{array}{l}\text { 1. VALORES E } \\
\text { TRANSPARÊNCIA }\end{array}$ & $\begin{array}{l}\text { Adote valores e } \\
\text { trabalhe com } \\
\text { transparência: esses } \\
\text { valores devem ser } \\
\text { divulgados } \\
\text { amplamente entre } \\
\text { todos da empresa que } \\
\text { sejam interiorizados; }\end{array}$ & $\begin{array}{l}\text { 2. Práticas Antipropina } \\
\text { 3. Práticas } \\
\text { Anticorrupção } \\
\text { 4. Balanço Social } \\
\text { 5. Governança } \\
\text { Corporativa }\end{array}$ & $\begin{array}{l}\text { 1. A empresa adota um conjunto de comportamentos a serem } \\
\text { praticados nas relações pessoais e comerciais, amplamente } \\
\text { divulgados mediante documento escrito e visível a todos os } \\
\text { frequentadores da empresa? } \\
\text { 2. Na empresa é proibido dar ou receber propinas e favores } \\
\text { pessoais ilícitos e isto é amplamente divulgado mediante } \\
\text { documento escrito? } \\
\text { 3. A empresa mantém um relacionamento ético e transparente } \\
\text { com o governo? Exemplos: age com transparência nos balanços } \\
\text { e registros em geral; proibe práticas de sonegação como “caixa } \\
\text { dois"; é rigorosa quanto à emissão de nota fiscal de todos os } \\
\text { produtos adquiridos e fornecidos; divulga instruções escritas } \\
\text { sobre como seus colaboradores devem se relacionar com o } \\
\text { governo. } \\
\text { 4. A empresa tem informações sobre balanço social, elabora e } \\
\text { divulga seu balanço social? } \\
\text { 5. Os negócios da empresa e os negócios do proprietário não se } \\
\text { misturam, pois existe separação clara entre eles? }\end{array}$ \\
\hline
\end{tabular}


Aferição do grau de responsabilidade social empresarial em MPES de Jundiaí e Região

\begin{tabular}{|c|c|c|c|}
\hline 2. PÚBLICO INTERNO & $\begin{array}{l}\text { Valorize os } \\
\text { funcionários e todos } \\
\text { os colaboradores: } \\
\text { cumprir a legislação } \\
\text { trabalhista, encorajar } \\
\text { novas ideias e } \\
\text { comentários; } \\
\text { desenvolver } \\
\text { programas de } \\
\text { remuneração e } \\
\text { incentivo; promover } \\
\text { diversidade cultural, } \\
\text { étnica, religiosa, de } \\
\text { orientação sexual e de } \\
\text { gênero, entre outras } \\
\text { medidas; }\end{array}$ & $\begin{array}{l}\text { 6. Cuidados com } \\
\text { Saúde, Segurança e } \\
\text { Condições de Trabalho } \\
\text { 7. Benefícios Adicionais } \\
\text { 8. Critérios de } \\
\text { contratação } \\
\text { 9. Valorização da } \\
\text { Diversidade e } \\
\text { Promoção da Equidade } \\
\text { 10. Inclusão de Pessoas } \\
\text { com Deficiência }\end{array}$ & $\begin{array}{l}\text { 6. A empresa se preocupa em oferecer aos seus colaboradores } \\
\text { um ambiente físico agradável e seguro, incentiva práticas de } \\
\text { higiene e saúde, ouve a opinião de seus colaboradores e está } \\
\text { aberta a críticas e sugestões? } \\
\text { 7. A empresa oferece benefícios adicionais aos empregados e aos } \\
\text { seus dependentes? Exemplos: plano de saúde familiar; cesta } \\
\text { básica; orientação sobre prevenção de doenças; orientações } \\
\text { acerca de campanhas de vacinação; creche no local de trabalho } \\
\text { ou em rede conveniada; auxílio-alimentação. } \\
\text { 8. Na contratação de empregados, a empresa divulga os critérios } \\
\text { objetivos que vai utilizar na seleção de candidatos? Exemplos: } \\
\text { escolaridade, tempo de experiência e conhecimentos exigidos. } \\
\text { 9. A contratação de pessoal é isenta de discriminação quanto ao } \\
\text { gênero, raça, orientação sexual, idade, crenças e deficiências? } \\
\text { Exemplos: a empresa não utiliza termos pejorativos (tais como } \\
\text { "idade máxima } 40 \text { anos", "boa aparência”, "sexo masculino", } \\
\text { "sexo feminino"); oferece vagas para ex detentos; mantém } \\
\text { programa especial para a contratação de idosos; disponibiliza } \\
\text { vagas para aprendizes, pessoas com deficiências, com mais de } \\
45 \text { anos de idade, indígenas e negros. } \\
\text { 10. Os empregados da empresa são treinados e orientados, por } \\
\text { escrito, para conviver com pessoas portadoras de deficiência e } \\
\text { atendê-las adequadamente? O local é acessível para essas } \\
\text { pessoas? }\end{array}$ \\
\hline & & $\begin{array}{l}\text { 11. Relações com } \\
\text { Sindicatos } \\
\text { 12. Compromisso com } \\
\text { o Desenvolvimento } \\
\text { Profissional e a } \\
\text { Empregabilidade } \\
\text { 13. Acesso à } \\
\text { Informação }\end{array}$ & $\begin{array}{l}\text { 11. A empresa entende que é direito do funcionário participar } \\
\text { de sindicatos e associações de classe? Exemplos: permite que } \\
\text { representantes sindicais compareçam à empresa para discutir } \\
\text { questões referentes aos interesses dos empregados; disponibiliza } \\
\text { informações básicas sobre direitos e deveres da categoria tais } \\
\text { como dissídios, contribuições sindicais etc. } \\
\text { 12. A empresa estimula o desenvolvimento profissional de seus } \\
\text { colaboradores subsidiando cursos, estágios etc.? A empresa } \\
\text { possui plano de carreira ou oferece aos seus colaboradores a } \\
\text { oportunidade de progredir dentro da organização? } \\
\text { 13. A empresa facilita o acesso à informação como forma de } \\
\text { desenvolvimento pessoal e profissional de seus colaboradores? } \\
\text { Exemplos: disponibilização de jornais, revistas e acesso à } \\
\text { internet em horários preestabelecidos etc. }\end{array}$ \\
\hline
\end{tabular}




\begin{tabular}{|c|c|c|c|}
\hline 3. MEIO AMBIENTE & $\begin{array}{l}\text { Faça sempre mais } \\
\text { pelo meio ambiente: } \\
\text { evitar o desperdício } \\
\text { dos insumos (energia, } \\
\text { matérias-primas em } \\
\text { geral, água); } \\
\text { promover coleta } \\
\text { seletiva de lixo; } \\
\text { redução de ruídos, } \\
\text { entre outras ações de } \\
\text { preservação } \\
\text { ambiental que, além } \\
\text { disso, são capazes de } \\
\text { reduzir gastos e até } \\
\text { mesmo gerar receita; }\end{array}$ & $\begin{array}{l}\text { 14. Gerenciamento dos } \\
\text { Impactos sobre o Meio } \\
\text { Ambiente e do Ciclo de } \\
\text { Vida de Produtos e } \\
\text { Serviços } \\
\text { 15.Comprometimento } \\
\text { da Empresa com a } \\
\text { Melhoria da Qualidade } \\
\text { Ambiental } \\
\text { 16. Educação e } \\
\text { Conscientização } \\
\text { Ambiental }\end{array}$ & $\begin{array}{l}\text { 14. A empresa conhece os impactos de suas atividades sobre o } \\
\text { meio ambiente e mantém relatórios periódicos para medir esses } \\
\text { impactos? Exemplos: emissão de poluentes, erosão do solo, alto } \\
\text { consumo de energia, de água, de combustíveis etc. } \\
\text { 15. A empresa procura implementar em suas atividades ações } \\
\text { que visam preservar o meio ambiente? Exemplos: utiliza } \\
\text { materiais que causem menos danos ao meio ambiente; procura } \\
\text { reduzir a poluição sonora e a poluição visual; realiza coleta } \\
\text { seletiva de lixo, economia no consumo de papel, redução do } \\
\text { consumo de energia, redução no consumo de água, comprar de } \\
\text { fornecedores que não prejudiquem o meio ambiente etc. } \\
\text { 16. A empresa promove a educação ambiental para os } \\
\text { empregados, familiares destes e para a comunidade? Exemplos: } \\
\text { incentivo ao transporte solidário, utilização de meios de } \\
\text { transporte que não prejudiquem o meio ambiente; informações } \\
\text { sobre quais são as áreas protegidas e os animais ameaçados na } \\
\text { região em que está instalada; apoia iniciativas e projetos } \\
\text { voltados para a educação ambiental, promove campanhas para } \\
\text { reciclagem de materiais, descarte adequado de resíduos tóxicos } \\
\text { e campanhas para a redução do consumo de água e energia etc. }\end{array}$ \\
\hline 4.FORNECEDORES & $\begin{array}{l}\text { Envolva parceiros e } \\
\text { fornecedores: a } \\
\text { empresa deve } \\
\text { estabelecer diálogo, } \\
\text { divulgando seus } \\
\text { valores aos parceiros } \\
\text { e fornecedores, } \\
\text { evitando contratar } \\
\text { serviços de } \\
\text { organizações que não } \\
\text { atuem com } \\
\text { responsabilidade } \\
\text { socioambiental; }\end{array}$ & $\begin{array}{l}\text { 18. Empregados dos } \\
\text { Fornecedores } \\
\text { 19. Responsabilidade } \\
\text { Social dos Fornecedores }\end{array}$ & $\begin{array}{l}\text { 17. Na contratação de um fornecedor, a empresa avalia se ele } \\
\text { mantém práticas de responsabilidade social? Exemplos: se o } \\
\text { fornecedor adota critérios de compra que levam em conta a } \\
\text { garantia de origem, para evitar a aquisição de produtos piratas, } \\
\text { falsificados ou frutos de roubo de carga; verifica se o fornecedor } \\
\text { adota algum sistema de certificação ambiental de seus produtos; } \\
\text { verifica se os fornecedores mantêm relações éticas e } \\
\text { transparentes com os concorrentes etc. } \\
\text { 18. A empresa avalia constantemente as condições } \\
\text { proporcionadas por seus fornecedores aos próprios } \\
\text { empregados? Exemplos: verifica se o fornecedor cumpre a } \\
\text { legislação trabalhista, previdenciária e fiscal; verifica se são boas } \\
\text { as condições de trabalho que ele proporciona aos próprios } \\
\text { colaboradores. } \\
\text { 19. A empresa organiza ou participa de programas e atividades } \\
\text { de responsabilidade social em parceria com seus fornecedores, } \\
\text { ou se dispõe a ajudá-los na sua implantação? Exemplos: ações } \\
\text { voltadas para a inclusão de portadores de necessidades } \\
\text { especiais, erradicação do trabalho infantil da cadeia produtiva, } \\
\text { combate à sonegação, proteção ambiental etc. }\end{array}$ \\
\hline
\end{tabular}


Aferição do grau de Responsabilidade social empresarial em MPES de Jundiaí e Região

\begin{tabular}{|c|c|c|c|}
\hline & & $\begin{array}{l}\text { 20. Apoio ao } \\
\text { Desenvolvimento de } \\
\text { Fornecedores }\end{array}$ & $\begin{array}{l}\text { 20. A empresa busca fornecedores em cooperativas de pequenos } \\
\text { produtores, associações de bairro e projetos de geração de } \\
\text { renda? Exemplos: cooperativas de artesãos, incubadora de } \\
\text { negócios, outras micro ou pequenas empresas etc.) e estimula a } \\
\text { formalização e a capacitação dos pequenos fornecedores, } \\
\text { ajudando-os a se adequarem aos padrões de mercado. }\end{array}$ \\
\hline $\begin{array}{l}\text { 5. CONSUMIDORES E } \\
\text { CLIENTES }\end{array}$ & $\begin{array}{l}\text { Proteja clientes e } \\
\text { consumidores: } \\
\text { oferecer qualidade, } \\
\text { eficiência e } \\
\text { credibilidade não } \\
\text { apenas durante o } \\
\text { processo de venda, } \\
\text { mas em toda sua } \\
\text { rotina de trabalho; }\end{array}$ & $\begin{array}{l}\text { 21. Excelência do } \\
\text { Atendimento } \\
\text { 22. Análise das } \\
\text { Dúvidas, Sugestões e } \\
\text { Reclamações } \\
\text { 23. Pesquisa de } \\
\text { Satisfação dos } \\
\text { Consumidores / } \\
\text { Clientes } \\
\text { 24. Política de } \\
\text { Comunicação } \\
\text { Comercial }\end{array}$ & $\begin{array}{l}\text { 24. Em suas mensagens publicitárias, contratos comerciais e nos } \\
\text { negócios, em geral, a empresa evita usar expressões } \\
\text { constrangedoras ou que possam induzir alguém a erro, e } \\
\text { incentiva os seus clientes ao uso responsável de seus } \\
\text { produtos/serviços? Exemplos: não faz propaganda enganosa, } \\
\text { não promete o que não conseguirá cumprir, não utiliza } \\
\text { expressões discriminatórias ou desrespeitosas, incentiva o } \\
\text { descarte adequado de embalagens etc. } \\
\text { 25. A empresa procura reduzir ou evitar os riscos que seus } \\
\text { produtos/serviços podem causar à saúde, à segurança ou à } \\
\text { privacidade de seus consumidores/clientes? Exemplos: pesquisa } \\
\text { e divulga os riscos e adota as medidas legais relativas à } \\
\text { comercialização responsável do seu produto (tais como não } \\
\text { vender cigarros a menores); preserva o sigilo de seus clientes e } \\
\text { contatos comerciais (só fornece informações cadastrais de um } \\
\text { cliente a terceiros mediante autorização dele). }\end{array}$ \\
\hline
\end{tabular}




\begin{tabular}{|c|c|c|c|}
\hline 6. COMUNIDADE & $\begin{array}{l}\text { Promova sua } \\
\text { comunidade: buscar } \\
\text { entrosamento com o } \\
\text { meio social onde atua, } \\
\text { com respeito aos } \\
\text { costumes e à cultura } \\
\text { local; contribuir em } \\
\text { projetos educacionais; } \\
\text { identificar problemas } \\
\text { e buscar soluções } \\
\text { conjuntas; praticar } \\
\text { filantropia etc.; }\end{array}$ & $\begin{array}{l}\text { 26. Gerenciamento do } \\
\text { Impacto da Empresa na } \\
\text { Comunidade de } \\
\text { Entorno } \\
\text { 27. Relações com a } \\
\text { Comunidade de } \\
\text { Entorno } \\
\text { Comunitária } \\
\text { Trabalho Voluntário } \\
\text { 31. Participação } \\
\text { Entidades Beneficiadas } \\
\text { Social } \\
\text { Empresa com a Ação } \\
\text { Envolvimento da }\end{array}$ & 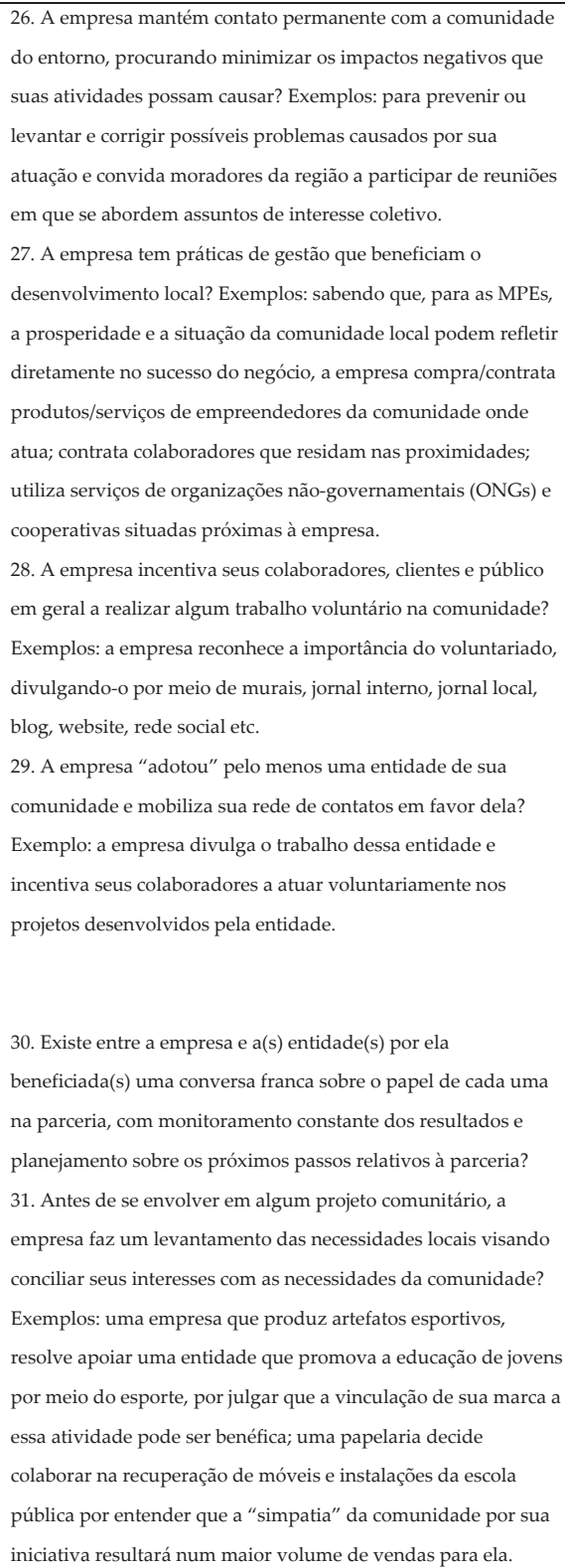 \\
\hline
\end{tabular}




\begin{tabular}{|c|c|c|c|}
\hline & & $\begin{array}{l}\text { 32. Benefícios para o } \\
\text { Negócio } \\
\text { 33. Participação e } \\
\text { Influência social }\end{array}$ & $\begin{array}{l}\text { 32. A empresa acredita que obteve benefícios para o negócio } \\
\text { como resultado de sua atuação em favor da comunidade e das } \\
\text { entidades beneficiadas? Exemplos: o aumento das vendas, a } \\
\text { melhoria na relação com os fornecedores, a aquisição de novos } \\
\text { contatos ou clientes, menor rotatividade de pessoal, economia } \\
\text { de itens como segurança e manutenção do prédio etc. } \\
\text { 33. A empresa participa de organizações e de eventos que } \\
\text { integrem empresários, para atualizar-se e discutir questões } \\
\text { relativas aos negócios e à comunidade? Exemplos: associações } \\
\text { comerciais e empresariais, fóruns regionais, simpósios etc. }\end{array}$ \\
\hline $\begin{array}{l}\text { 7. GOVERNO E } \\
\text { SOCIEDADE }\end{array}$ & $\begin{array}{l}\text { Comprometa-se com } \\
\text { o bem comum: } \\
\text { manter } \\
\text { relacionamento ético } \\
\text { com o poder público; } \\
\text { cumprir as leis; } \\
\text { honrar os } \\
\text { compromissos fiscais; } \\
\text { combater a corrupção; } \\
\text { contribuir para } \\
\text { projetos e ações } \\
\text { governamentais } \\
\text { voltados para a área } \\
\text { social etc. }\end{array}$ & $\begin{array}{l}\text { 34. Envolvimento em } \\
\text { Campanhas Políticas } \\
\text { 35. Participação e } \\
\text { Acompanhamento das } \\
\text { Administrações } \\
\text { Públicas } \\
\text { 36. Melhoria dos } \\
\text { Espaços Públicos e } \\
\text { Apoio a Iniciativas } \\
\text { Sociais Governamentais }\end{array}$ & $\begin{array}{l}\text { 34. A empresa é criteriosa sobre seu envolvimento em } \\
\text { campanhas políticas? Exemplos: promove debates eleitorais; } \\
\text { estimula o voto consciente; é transparente quando decide apoiar } \\
\text { algum candidato ou partido político e analisa cuidadosamente a } \\
\text { distribuição de material de campanhas políticas. } \\
\text { 35. A empresa informa aos seus colaboradores sobre a } \\
\text { importância de participar dos assuntos de interesse público e a } \\
\text { fiscalizar ações realizadas pelas administrações públicas? } \\
\text { Exemplos: opinar sobre o orçamento participativo, participar } \\
\text { das eleições de conselhos municipais, consultas públicas etc. } \\
\text { 36. Sempre que necessário (e possível), a empresa colabora com } \\
\text { a melhoria dos espaços públicos da sua região e apoia as ações } \\
\text { sociais do governo? Exemplo: esclarece os colaboradores sobre } \\
\text { como utilizar o abatimento no imposto de renda em favor de } \\
\text { fundos sociais. }\end{array}$ \\
\hline
\end{tabular}

\section{Quadro 1 - As Sete Diretrizes da RSE e seus respectivos indicadores} Fontes: elaborado com dados de Ethos-Sebrae (2003 e 2013).

As respostas objetivas contemplaram cinco alternativas numeradas, cujos números encerram o próprio valor qualitativo atinente ao desempenho da empresa objeto da entrevista, conforme explicitado a seguir:

1. NÃO - A situação retratada não está inserida na prática da empresa;

2. UM POUCO - A situação retratada é pouco praticada ou raramente ocorre;

3. EM PARTE - Alguns dos fatores retratados na situação fazem parte do cotidiano da empresa;

4. EM GRANDE PARTE - A situação retrata uma condição muito próxima da realidade da empresa;

5. SIM - A situação descrita faz parte integral da realidade 
da empresa.

As empresas foram escolhidas aleatoriamente e contatadas por telefone, e-mail ou pessoalmente, sendo convidadas a participar da pesquisa, após terem sido esclarecidas sobre seus propósitos, sendo selecionadas as dezoito primeiras que atenderam aos seguintes requisitos:

a) As empresas participantes deveriam ser micro ou pequenas empresas, assim consideradas quanto ao critério econômico, ou seja: com receita bruta anual não superior a $\mathrm{R} \$$ 4.800.000,00 (quatro mihões e oitocentos mil reais);

b) As MPEs participantes deveriam ter estabelecimento em algum dos municípios que compõem o AUJ, tendo em vista o escopo da pesquisa;

c) Elas deveriam ter, no mínimo, cinco (5) colaboradores fixos, a fim de assegurar que os dados obtidos tivessem um mínimo de relevância socioeconômica;

d) O número de participantes deveria ser de, pelo menos, 18 empresas, para que se obtivesse um mínimo de relevância nos dados obtidos com as amostras;

e) A quantidade de empresas participantes deveria observar a igualdade na distribuição entre os Setores da Indústria, Comércio e Serviços, para garantir igualdade de valor nas amostras por setor.

f) A seleção das empresas e coleta de dados deveria ser realizada entre os meses de novembro e dezembro de 2016, conforme estabelecido no Cronograma aprovado pela Banca Examinadora.

Os dados foram obtidos junto a dezoito MPEs, distribuídas proporcionalmente pelos setores da Indústria, Comércio e Serviços, em três localidades pertencentes ao AUJ (Jundiaí, Várzea Paulista e Campo Limpo Paulista).

Tendo em vista a reduzida quantidade de amostras, buscou-se a máxima diversidade, pesquisando-se empresas de variados ramos e grande diversidade de tempo de atividade, número de colaboradores e de receita bruta anual, conforme explicitado na Seção 4 Resultados e Discussão.

Para tratamento dos dados, foram elaborados gráficos, quadros 
e tabelas contendo os resultados estatísticos, calculados a partir das informações obtidas por meio das respostas fornecidas pelos participantes durante as entrevistas. Adotou-se a metodologia do Balanço Perguntado que, segundo Kassai (2006), consiste basicamente, no "interrogatório direto ao dono ou pessoa responsável pelo empreendimento e, com base em suas respostas, na experiência do perguntador e em alguns ajustes de consistência, obter as informações necessárias".

Tendo em vista que o objetivo geral é a aferição do Grau de Responsabilidade Social Empresarial dos estabelecimentos pesquisados, esta será realizada individual e coletivamente, tomando-se por base a relação percentual entre a pontuação máxima possível (36 questões valendo 5 pontos cada) e a pontuação obtida pelas empresas pesquisadas, do seguinte modo:

a) Grau de RSE individual: pontuação obtida pela empresa / pontuação individual máxima possível $(36$ X5=180) = grau máximo (100\%)

b) Grau de RSE coletivo: soma dos pontos obtidos pelas 18 empresas / pontuação coletiva máxima possível $(180 X 18=3240)$ = grau máximo $(100 \%)$

Para atingir os objetivos específicos desta pesquisa, a aferição do grau de incidência das Sete Diretrizes da RSE e seus respectivos Indicadores, se usará método análogo ao já descrito, além de apontar o tipo de resposta que predominou em cada uma das questões e as respectivas explicações dadas pelos entrevistados.

Os mesmos dados foram utilizados para comparar as empresas pesquisadas, ordenando os resultados de acordo com os seguintes critérios: setor econômico, tempo de atividade, número de colaboradores e receita bruta anual.

Em cada uma das aferições, o grau de RSE foi estabelecido pela seguinte relação entre a pontuação obtida e a faixa percentual do grau correspondente: de $0 \%$ a 19,99\%: BAIXO; de 20\% a 39,99\%: MÉDIO-BAIXO; de $40 \%$ a 59,99\%: MÉDIO; de $60 \%$ a $79,99 \%$ : MÉDIO-ALTO; de $80 \%$ a $100 \%$ : ALTO.

Levando-se em consideração a quantidade de empresas instaladas na AUJ, esta pesquisa encontra-se limitada pela reduzida quantidade de amostras, decorrente de limitações operacionais, o 
que, além de restringir a eficácia dos dados quantitativos, também impossibilitou a distribuição proporcional da coleta dos dados entre as localidades e os setores econômicos.

No entanto, a escolha da abordagem qualitativa, pelo método de triangulação, leva em conta a diversidade entre as características das dezoito empresas pesquisadas no que se refere aos setores econômicos a que pertencem, ramos em que atuam, sua localização, número de colaboradores e receita bruta anual. Além disso, os dados desta pesquisa têm como fonte as respostas dadas pelos próprios gestores (com a correspondente carga de subjetividade que isso implica), de modo que a triangulação com dados quantitativos (ainda que com reduzida quantidade de amostras), permite o cruzamento entre informações por eles fornecidas no Questionário e na Entrevista, em combinação com o emprego da técnica de Observação por parte do pesquisador, o que possibilitou a obtenção de resultados confiáveis.

\section{RESULTADOS E DISCUSSÃo}

As dezoito empresas participantes foram identificadas com números que vão de 1 a 18 e, para um conhecimento mais claro sobre suas características, elas foram relacionadas numa listagem contendo: número de ordem da entrevista (E); setor econômico (SET); ramo de atuação; tempo (anos) em atividade (T.A.); quantidade de colaboradores (Quant. Colab.), e receita bruta anual (em milhões de reais), conforme explicitado na Tabela 1 :

Tabela 1 - Relação das empresas participantes da pesquisa e suas principais características

\begin{tabular}{l|l|l|l|l|l|l}
\hline E & MUN. & SET. & RAMO & $\begin{array}{l}\text { T.A. } \\
\text { (anos) }\end{array}$ & $\begin{array}{l}\text { Quant. } \\
\text { Colab. }\end{array}$ & $\begin{array}{l}\text { Receita Bruta } \\
\text { Anual (mi- } \\
\text { lhões de R\$) }\end{array}$ \\
\hline 1 & JDI & COM & Restaurante fast food (franquia) & 1 & 13 & 0,32 \\
\hline 2 & JDI & IND & Cervejaria artesanal & 3 & 6 & 0,25 \\
\hline 3 & CLP & COM & Materiais para Construção & 28 & 10 & 0,30 \\
\hline 4 & JDI & SERV & Advocacia & 15 & 9 & 3,30 \\
\hline 5 & JDI & SERV & Contabilidade & 37 & 36 & 2,12 \\
\hline 6 & CLP & COM & Produtos agropecuários & 38 & 18 & 0,30 \\
\hline
\end{tabular}




\begin{tabular}{l|l|l|l|l|l|l}
\hline 7 & VP & COM & Bombas hidráulicas & 15 & 6 & 0,19 \\
\hline 8 & JDI & SERV & Clínica Veterinária & 34 & 8 & 1,20 \\
\hline 9 & JDI & COM & Automóveis & 42 & 30 & 4,56 \\
\hline 10 & JDI & COM & Chocolates (franquia) & 3 & 5 & 0,70 \\
\hline 11 & JDI & SERV & Advocacia & 18 & 6 & 0,78 \\
\hline 12 & JDI & IND & Molduras e Porta-retratos & 13 & 16 & 0,95 \\
\hline 13 & VP & IND & Colchões & 18 & 27 & 2,30 \\
\hline 14 & VP & SERV & $\begin{array}{l}\text { Desenvolvimento de Softwares e } \\
\text { Redes }\end{array}$ & 7 & 5 & 0,11 \\
\hline 15 & JDI & IND & Construção Civil & 25 & 17 & 1,50 \\
\hline 16 & VP & IND & Máquinas e peças mecânicas & 12 & 6 & 0,50 \\
\hline 17 & JDI & SERV & Escola infantil & 21 & 12 & 0,37 \\
\hline 18 & JDI & IND & Torrefação e moagem de café & 67 & 37 & 4,79 \\
\hline
\end{tabular}

Fonte: elaborado com base na pesquisa.

Quanto aos Objetivos Gerais, as empresas pesquisadas, analisadas em seu conjunto, obtiveram 66,20 pontos percentuais, o que, de acordo com o padrão adotado, confere a elas o grau médio-alto de RSE.

No que toca à aplicação das 7 Diretrizes da RSE, as empresas apresentaram alto grau de desempenho com relação a Consumidores e Clientes (93,6\%) e Público Interno (80\%); grau médio-alto em Meio Ambiente (67\%) e Valores, Transparência e Governança Corporativa $(63,1 \%)$. Porém, seu desempenho foi apenas mediano com relação à Comunidade $(55,8 \%)$, aos Fornecedores (50,8\%), obtendo grau médio-baixo com relação ao Governo e Sociedade (36,3\%).

Quanto aos Objetivos Específicos, a comparação dos dados revelou relativo equilíbrio no desempenho entre Setores de Serviços $(69,2 \%)$ e Comércio $(68,5 \%)$, com resultado inferior por parte da Indústria (60,9\%).

A análise de desempenho quanto aos $\underline{\text { Indicadores aponta que }}$ os três de melhor desempenho são:

- Q22 - Análise das dúvidas e sugestões (Consumidores e Clientes): 97,78;

- Q24 - Política de comunicação comercial (Consumidores e Clientes): 97,78;

- Q6 - Cuidados com Saúde, segurança e condições de traba- 
lho (Público interno): 96,67;

Já os três Indicadores de pior desempenho são:

- Q19 - Responsabilidade social dos fornecedores (Fornecedores): 31,11 ;

- Q30 - Relação com entidades beneficiadas (Comunidade): 30,00;

- Q4 - Balanço Social (Valores, Transparência e Governança Corporativa): 28,89;

Quanto ao tempo de atividade, notou-se aumento gradual da pontuação conforme aumento da faixa etária, sendo que as empresas mais jovens (até 5 anos) obtiveram $56,7 \%$ e as mais velhas (mais de 20 anos) atingiram 71,9\%. Tal desempenho confirma os estudos de Audretsch (1995), de que empresas que tendem a sobreviver são aquelas que têm um tamanho maior, investem mais em inovação e, portanto, crescem mais rápido.

Outro indicativo da existência de relação direta entre idade e desempenho se estabelece pela constatação de que, na aferição individual, a que obteve melhor desempenho e única com grau alto de RSE (E3, com 84,4\%), é antiga (28 anos em atividade). Por sua vez, a empresa que obteve pior desempenho individual e única que ficou com grau médio-baixo (E2, com 46,1\%), é jovem (3 anos).

Entretanto, esses resultados não permitem concluir qual é o tipo de relação existente entre tempo de atividade e RSE. Em outras palavras: não foi possível identificar se (e até que ponto) as empresas são mais longevas porque atuaram com maior grau de RSE, ou se (e até que ponto) possuem maior grau de RSE porque a idade lhes trouxe maiores habilidades. Portanto, essa questão demanda maior aprofundamento, a ser efetuado por meio de outras pesquisas.

A comparação dos desempenhos quanto ao número de colaboradores revela relativo equilíbrio entre as três faixas em que essa categoria foi distribuída, observando-se em todas elas o grau médio-alto de aproveitamento, onde a pontuação mínima foi $61,44 \%$ e a máxima foi $71,67 \%$.

Porém, não foi possível estabelecer ou inferir a existência de relação entre número de colaboradores e desempenho.

De igual modo, a análise por receita bruta anual também revela equilíbrio entre as três faixas em que os dados foram distribuídos, 
sendo que as três obtiveram grau médio-alto na aferição da RSE, percebendo-se melhor desempenho entre as duas faixas mais altas, o que indica a existência de relação direta entre receita bruta e desempenho.

Porém, este estudo não possibilitou compreender se (e até que ponto) a atuação com RSE influiu para que essas empresas atingissem o elevado patamar de sua renda bruta anual, ou se (e até que ponto) seu relativo conforto lhes permitiu atuar com RSE. Portanto, para que isso possa ser melhor compreendido, torna-se necessária futura realização de outros estudos, mais específicos.

Em que pesem os resultados em geral satisfatórios, a pesquisa também revelou dezessete deficiências que, apesar de pouco aparentes e minoritárias, devem ser destacadas:

1. Informalidade excessiva: em $44,4 \%$ das empresas entrevistadas não existem regras de conduta quanto a compromissos éticos, práticas antipropina e anticorrupção; sendo notada excessiva improvisação, e ausência de registro quanto ao gerenciamento dos impactos das atividades sobre o meio ambiente e sobre a comunidade de entorno;

2. Autocracia e Falta de transparência: igual porcentagem se aplica às empresas que declararam não compartilhar informações estratégicas com o público interno e não divulgar ao público externo as regras de conduta adotadas pela empresa (Indicadores 1, 2, 3), os critérios de contratação (Indicador 8); e que também admitiram proibir ou restringir o acesso de representantes sindicais (Indicador 11).

3. Imprecisão ou insuficiência de dados gerenciais: em consequência dos fatos apontados nos itens 1 e 2, os gestores demonstraram ter apenas uma noção vaga e imprecisa relativa a diversos fatores estratégicos da empresa, por falta ou insuficiência de registros escritos, sendo que 100\% dos entrevistados informaram que não realizam Balanço Social e $61,1 \%$ deles admitiram que nem sequer ouviram falar a respeito.

4. Pagamento de propina: alguns gestores alegaram a necessidade de pagar "gratificações" a gestores de outras empresas e de entidades públicas para obter a preferência na contra- 
tação de serviços (Indicador 2).

5. Sonegação fiscal: Os gestores mencionados na análise do Indicador 3 (Práticas Anticorrupção) admitiram realizar compra ou venda "sem nota", "com nota por baixo" e praticar "caixa dois" etc., sob alegação de que "se não fizer isso a gente não sobrevive" e "o governo tira muito e não dá nada em troca".

6. Confusão patrimonial: quase $40 \%$ dos gestores admitiram que, no todo ou em parte, ocorre confusão entre o patrimônio da empresa e dos sócios (Indicador 5 - Governança Corporativa), o que também confirma a literatura coligida, expressa na Seção 2, citando a existência de estreito vínculo entre os proprietários e as empresas, não se distinguindo, principalmente em termos contábeis e financeiros, pessoa física e jurídica (IBGE, 2013).

7. Problemas de acessibilidade: em diferentes graduações e modos, 44,4\% apresentam problemas com relação aos portadores de necessidades especiais (Indicador 10), seja por dificuldade de acesso (obstáculos físicos) ou de interação (despreparo dos colaboradores para o atendimento desse público).

8. Limitações ao desenvolvimento profissional e à empregabilidade: $27,8 \%$ dos gestores apresentaram ao menos uma das seguintes limitações: "dificuldades financeiras para pagar os estudos dos empregados" e "inexistência de plano de carreira". Alguns gestores declararam que "isso não traria qualquer retorno ou benefício para o negócio" (Indicador 12), o que também confirma a literatura citada na Seção 2 deste trabalho, dando conta de que uma das principais características das MPEs é a contratação de mão de obra não qualificada ou semiqualificada (IBGE, 2013).

9. Limitação de acesso à informação: 38,9\% dos gestores informaram que o acesso dos colaboradores à informação existe com restrição de horário ou nem existe (Indicador 13), alegando impossibilidade operacional devido à natureza do serviço.

10. Inexistência de práticas de Educação e Conscientização 
Ambiental: 77,8\% dos entrevistados declararam que, quando necessário às atividades da empresa, dão orientações aos colaboradores, mas afirmaram que não há qualquer procedimento voltado para os familiares destes ou para a comunidade.

11. Desinteresse quanto à responsabilidade social dos fornecedores: 77,8\% dos gestores admitiram que a empresa não avalia as condições proporcionadas por seus fornecedores aos próprios empregados, e 94,5\% afirmaram que sua empresa não organiza nem participa de qualquer programa ou atividade de RSE em conjunto com seus fornecedores (Indicador 19).

12. Desinteresse quanto ao desenvolvimento dos fornecedores locais: $72,2 \%$ dos gestores informaram que não mantêm negócios com fornecedores locais, ou o fazem raramente.

13. Isolacionismo: $33,3 \%$ dos entrevistados informaram que sua empresa não mantém qualquer contato com a comunidade de entorno para o gerenciamento do impacto de suas atividades, ou declarando que o contato é muito raro (Indicador 26) e $44,4 \%$ deles informaram que não adotam qualquer prática voltada para o desenvolvimento da comunidade local, também afirmando que não há qualquer preferência pela contratação de mão de obra local.

14. Desinteresse pelo Voluntariado e pela Ação Social: $55,6 \%$ dos entrevistados afirmaram que suas empresas não realizam qualquer atividade beneficente/assistencial, ou o fazem eventualmente; tem pouco ou nenhum envolvimento com ação social, sob alegação de excesso de compromissos relativos à empresa, entre outras (Indicadores 28 e 29), o que demonstra relativa falta de comprometimento com o bem comum.

15. Ausência de Planejamento Estratégico nas relações com as entidades beneficiadas: entre as empresas que têm atuação constante em favor da comunidade, $94,4 \%$ dos gestores asseveraram que não existe qualquer conversa entre as empresas e as entidades beneficiadas sobre o papel de cada uma, pois não há parceria, compromissos mútuos, nem contrapartidas, 
esclarecendo que em seu contato com tais entidades, as empresas se limitam a obter informações sobre o que pode ser feito para ajudá-las (Indicador 30). No mesmo sentido, $83,3 \%$ dos gestores declararam que não existe qualquer levantamento prévio entre as necessidades das entidades e os interesses da empresa, sob alegação de que seu interesse não é mercadológico, mas exclusivamente beneficente (Indicador 31). Além disso, $83,3 \%$ deles afirmaram não ter percebido qualquer benefício decorrente de sua ação comunitária, compartilhando a visão de que, por atuarem com objetivo exclusivamente beneficente perante tais entidades, suas empresas nunca esperaram obter qualquer benefício para os negócios, admitindo que estes podem ocorrer direta ou indiretamente, em maior ou menor grau, ou até mesmo não ocorrer, mas como consequência eventual, nunca como um objetivo estratégico (Indicador 32).

16. Baixa participação e influência social: $44,4 \%$ dos gestores admitiram que têm pouca ou nenhuma interação junto aos seus pares, em reuniões, palestras ou entidades de classe, alegando que as atividades junto às respectivas empresas tomam todo ou quase todo seu tempo útil (Indicador 33).

17. Aversão por envolvimento em questões políticas e sociais: $66,7 \%$ das empresas pesquisadas evitam qualquer tipo de envolvimento em campanhas políticas, evitam tratar desse assunto e não adotam qualquer medida para conscientizar seus colaboradores quanto à importância do voto consciente. Quase todas elas manifestaram repulsa pela ideia de se envolverem com qualquer governo, mencionando os recentes escândalos de corrupção ocorridos no país (Indicador 34). Das empresas, 77,8\% evitam participar de ações promovidas pelas administrações públicas, umas alegando que essa conduta não se alinha com os objetivos da empresa, outras sustentando que parte da clientela poderia interpretar como sendo atitude político-partidária e que isso poderia ser prejudicial aos negócios (Indicador 35) e 83,3\% dos gestores responderam que preferem não se envolver em nada que 
diga respeito à administração pública (Indicador 36).

Os resultados apontados, ao cotejo com os resultados das pesquisas sobre RSE anteriormente realizadas na AUJ, trazem constatações tão semelhantes, que muitas delas podem ser reproduzidas ao estudo em discussão:

- Embora existam alguns núcleos de excelência na RSE, o tema ainda está longe de ser uma prioridade entre as MPEs da AUJ, ante a constatação da elevada proporção de empresas que ainda atuam sem responsabilidade social (TACHIZAWA e POZO, 2007).

- Grande parte das MPEs da AUJ possui baixo grau de proficiência (MELLO e TACHIZAWA, 2015) ante a evidência de que tais empresas: têm grande precariedade no conhecimento e utilização de insumos básicos como a tecnologia da informação (SACILOTTI, 2011); possuem baixo nível de conhecimentos teóricos acerca da Administração e das técnicas de gerenciamento (PICCHIAI, 2013).

- Os micro e pequenos empreendedores locais tendem a não perceber as vantagens que podem advir de uma administração feita com responsabilidade (TACHIZAWA e POZO, 2007), e mesmo entre as MPEs que reconhecem a importância de atuar com responsabilidade social, esses estudos constataram certa tendência ao imobilismo, pois estas pouco ou nada fazem nesse sentido (MELLO e TACHIZAWA, 2015).

\section{Considerações finais}

Os fatos mostrados levam à conclusão de que, apesar de terem obtido grau médio-alto na aferição de desempenho quanto à RSE, as MPEs do AUJ necessitam aprimorar suas práticas gerenciais, especialmente no que se refere às deficiências apontadas.

Tendo em vista tratar-se de estudo de caso coletivo, envolvendo empresas dos setores da Indústria, Comércio e Serviços, de múltiplos ramos, cujos resultados têm origem em situações, caracaterísticas e fatos específicos, impossível se torna, no exíguo espaço de uma só pesquisa, sugerir medidas saneadoras para cada um dos casos.

Porém, explicitando de um modo geral, pode-se sugerir que as empresas adotem o hábito de atuar com objetividade, planificando 
suas ações estratégicas e táticas, inclusive as de RSE.

Nesse particular aspecto, recomenda-se a utilização de algum método de planejamento, ação, controle e ajuste (ciclo PDCA), especialmente o Modelo proposto por Ethos-Sebrae (Seção 2.1.3), por ser especialmente voltado para a realidade das MPEs.

Devido às limitações operacionais, só foi possível selecionar, para esta pesquisa, 18 empresas, localizadas em três Municípios do AUJ, o que pode reduzir a magnitude de seus dados, por ser um número comparativamente reduzido, diante de um universo de 13.590 empresas estabelecidas nos 7 Municípios do AUJ (IBGE, 2010).

Tal fato recomenda a continuidade da pesquisa, até porque nem todos os aspectos relacionados ao tema foram profundamente estudados.

Por isso, sugere-se que novos estudos sejam realizados, ampliando-se o seu alcance e profundidade, nos moldes a seguir propostos:

- Quanto ao alcance: futura pesquisa deverá envolver um número maior de empresas, de modo a incluir os outros municípios pertencentes ao AUJ;

- Quanto à profundidade: a pesquisa visará estabelecer qual a relação existente entre o maior/menor grau de RSE com o maior/menor tempo de atividade e com a maior/menor renda das organizações a serem pesquisadas

\section{REFERÊNCIAS}

ABNT - ASSOCIAÇÃO BRASILEIRA DE NORMAS TÉCNICAS. NBR 16001:2012. Responsabilidade social - sistema de gestão - requisitos. Rio de Janeiro, 2012. Disponível em: https:// www.abntcatalogo.com.br/norma.aspx?ID=91309. Acesso em 28.01.2016.

ALMEIDA, F. Os Desafios da Sustentabilidade. Rio de Janeiro: Elsevier, 2007. Disponível para download em: http://93.174.95.27/ads.php?md5=bf1343e9374974634ed1179de20ce9bf. Acesso em 16.07.2016.

AUDRETSCH, D. B. Innovation and Industry Evolution. Massachusetts: MIT-Press, 1995.

AZEVEDO, C. E. F.; OLIVEIRA, L. G. L.; GONZALEZ, R. K.; ABDALLA, M. M. A estratégia de triangulação: objetivos, possibilidades, limitações e proximidades com o pragmatismo. In: Anais do IV Encontro de Ensino e Pesquisa em Administração e Contabilidade. ANPAD - Associação Nacional de Pós-graduação e Pesquisa em Administração, Brasília, 2013.

BICALHO, A. Responsabilidade Social das Empresas: Contribuição das Universidades. Editora Peirópolis, 2003, p. 364, São Paulo, 2003. 
BRASIL, República Federativa do. Decreto no ${ }^{\circ}$. 538, de 06.10.2015. Regulamenta o tratamento favorecido, diferenciado e simplificado para as microempresas, empresas de pequeno porte, agricultores familiares, produtores rurais pessoa física, microempreendedores individuais e sociedades cooperativas de consumo nas contratações públicas de bens, serviços e obras no âmbito da administração pública federal. Disponível em: http://www.planalto. gov.br/ccivil_03/_ato2015-2018/2015/decreto/d8538.htm. Acesso em: 20.03.2016.BRASIL. Lei Complementar $\mathbf{n}^{\circ}$. 123, de 14 de dezembro de 2006 (Estatuto Nacional da Microempresa e da Empresa de Pequeno Porte). Disponível em: http://www.planalto.gov.br/ccivil_03/leis/ LCP/Lcp123.htm\#art89. Acesso em 20.03.2016.

BRASIL. Lei Complementar n⿳0. 155, de 27 de outubro de 2016 (altera a Lei Complementar no. 123, de 14 de dezembro de 2006). Disponível em: https://www.planalto.gov.br/ccivil_03/ leis/LCP/Lcp155.htm. Acesso em 28.12.2016.

BRASIL. Lei n⿳o. 11.638, de 28 de dezembro de 2.007 (altera e revoga dispositivos da Lei n⿳o. 6.404, de 15 de dezembro de 1976, e da Lei no . 6.385, de 7 de dezembro de 1976, e estende às sociedades de grande porte disposições relativas à elaboração e divulgação de demonstrações financeiras). Disponível em: http://www.planalto.gov.br/ccivil_03/_ato2007-2010/2007/lei/ 111638.htm. Acesso em 23.07.2016.

CALDAS, C. B.; TAMBOSI FILHO, E.; VIEIRA, A. M. Governança Corporativa e Sustentabilidade: uma relação necessária. Revista UNIABEU, v. 7, p. 353-369, 2014.

CRESSWELL, J. W.; PLANO CLARK, V. L. Pesquisa de métodos mistos, 2. ed. Porto Alegre: Penso, 2013.

DAVIS, H. Business Mortality: The Shoe Manufactoring Industry. Harvard Business Review, v. 17, n. 3, p. 331-339, 1939.

ETHOS, Instituto de Empresas e Responsabilidade Social; SEBRAE - Serviço Brasileiro de Apoio às Micro e Pequenas Empresas. Responsabilidade social empresarial para micro e pequenas empresas passo a passo. Publicado por Ethos-Sebrae. São Paulo, outubro de 2003. Disponível em: http://www.bibliotecas.sebrae.com.br/chronus/ARQUIVOS_CHRONUS/bds/ bds.nsf/357151C893C7938983256E92005F13B5/\$File/NT00005622.pdf. Acesso em: 10.02.2016.

ETHOS, Instituto de Empresas e Responsabilidade Social; SEBRAE - Serviço Brasileiro de Apoio às Micro e Pequenas Empresas. Indicadores ethos-sebrae de responsabilidade social empresarial para micro e pequenas empresas. Publicado por Ethos-Sebrae. São Paulo, julho de 2013. Disponível em http://www3.ethos.org.br/wp-content/uploads/2013/07/IndicadoresEthos-Sebrae_2013_PORT.pdf. Acesso em: 10.02.2016.

FANELLI, A. F.i D. M.; SANTOS JÚNIOR, W. R. O Aglomerado Urbano de Jundiaí (SP) e os desafios para a mobilidade metropolitana paulista. Cadernos Metrópole, São Paulo, v. 15, n. 30, p. 461-487, dezembro de 2013. Disponível em:

< http://www.scielo.br/pdf/cm/v15n30/2236-9996-cm-15-30-0461.pdf>. Acesso em: 28.06.2016.

FLICK, U. Introdução à pesquisa qualitativa, 3. ed. Porto Alegre: Bookman, 2013.

IBGE - Instituto Brasileiro de Geografia e Estatística. Censo 2010. Disponível em: <http:// censo2010.ibge.gov.br>. Acesso em 19.02.2016. 
IBGE - Instituto Brasileiro de Geografia e Estatística. Estatísticas do Cadastro Central de Empresas. Brasília, 2010. Disponível em: < http://www.ibge.gov.br/home/estatistica/pesquisas/ pesquisa_resultados.php?id_pesquisa=9>. Acesso em 19.02.2016.

IBGE - Instituto Brasileiro de Geografia e Estatística. As micro e pequenas empresas no Brasil. Brasília, IBGE, 2013. Disponível em: http://www.ibge.gov.br/home/estatistica/economia/ microempresa/ Acesso em 19.02.2016.

KASSAI, J. R.; CASA NOVA, S. P. C. Pequenas Empresas - Como é difícil “levantar dinheiro"! Com Texto, Porto Alegre, v. 6, n. 9, 1‥ semestre 2006; ISSN (Impresso): 1676-6016 - ISSN (On-line): 2175-8751.

MATTIOLI, J. W.; CASTRO, D. S. P. ; CLARO, J. A. C. S.; VIEIRA, A. M.; SPERS, V. R. E. Corporate social responsibility and its role in the small business scenario. Nucleus (Ituverava. Impresso), v. 12, p. 285-302, 2015.

MELLO, C. Q. V. Responsabilidade social empresarial: uma análise do discurso do micro e do pequeno empresário do Distrito Federal. Universidade de Brasília. Publicado pelo Sebrae, 2004. Disponível em:

$<$ http://www.bibliotecas.sebrae.com.br/chronus/ARQUIVOS_CHRONUS/bds/bds.nsf/702b0954eb6ef2fd08266bf46273c7e5/\$File/1151.pdf>. Acesso em 06.02.2016.

MELLO, E.; TACHIZAWA, T. (Org.). Responsabilidade Socioambiental: uma análise das indústrias de Campo Limpo Paulista. In: Gestão e sustentabilidade. Editora Livros \& Cia Cultura e Lazer, $4^{\mathrm{a}}$ e. 2015.

PICCHIAI, D. Pequenas empresas: estruturas e competências. XVI Simpósio de Administração da Produção, Logística e Operações Internacionais - SIMPOI 2013. Realização Fundação Getúlio Vargas - São Paulo (FGV-SP) e Escola de Administração de Empresas de São Paulo (EAESP). São Paulo, 2013. Disponível em:

$<$ http://www.simpoi.fgvsp.br/arquivo/2013/artigos/E2013_T00142_PCN67719.pdf>. Acesso em: 04.02.2016.

SACILOTTI, A. C. A importância da tecnologia da informação nas micro e pequenas empresas: um estudo exploratório na região de Jundiaí. Dissertação de Mestrado em Administração, Faculdade Campo Limpo Paulista - FACCAMP. Disponível em: <http://www.faccamp.br/ madm/Documentos/producao_discente/2011/04abril/AdaniCusinSacilotti/dissertaCAo.pdf $>$. Acesso em 04.02.2016.

SÃO PAULO, Estado de. Lei Complementar Estadual noo. 1.146, de 17.08.2011 (Cria a Aglomeração Urbana de Jundiaí e dá providências correlatas). Disponível em: http://www.al.sp. gov.br/norma/?id=161913. Acesso em 20.03.2016.

SEBRAE - Serviço Brasileiro de Apoio às Micro e Pequenas Empresas; INTEGRARE Centro de Integração de Negócios. Práticas sustentáveis nas grandes empresas e suas demandas para as micro e pequenas empresas. Encadeamento produtivo. Brasília, 2013. Disponível em: <file://C:/Users/Walter\%20L.\%20Oliveira/Downloads/Pr\%C3\%A1ticas\%20 sustent $\%$ C3\%A1veis\%20nas\%20grandes\%20empresas\%20e\%20suas $\% 20$ demandas $\% 20$ para $\% 20$ micro\%20e\%20 pequenas\%20empresas.pdf>. Acesso em 06.02.2016. 
SEBRAE - Serviço Brasileiro de Apoio às Micro e Pequenas Empresas; INTEGRARE - Centro de Integração de Negócios. Sobrevivência das empresas no Brasil. Coleção Estudos e Pesquisas. Série Ambiente dos Pequenos Negócios. Brasília-DF. Outubro/2016. Disponível em: https://www.sebrae.com.br/Sebrae/Portal\%20Sebrae/Anexos/sobrevivencia-das-empresas-no-brasil-relatorio-2016.pdf. Acesso em 27.01.2017.SILVA, E. L.; MENEZES, E. M. Metodologia da Pesquisa e Elaboração de Dissertação, 3. ed. Florianópolis: UFSC, 2005. Disponível em: https://projetos.inf.ufsc.br/arquivos/Metodologia_de_pesquisa_e_elaboracao_de_teses_e_ dissertacoes_4ed.pdf. Acesso em 02.10.2016.

TACHIZAWA, T. Gestão Ambiental e Responsabilidade Social Corporativa: estratégias de negócios focadas na realidade brasileira, 8. edição. São Paulo: Atlas, 2015.

TACHIZAWA, T.; POZO, Hamilton. Gestão de recursos humanos em micro e pequenas empresas: um enfoque de gestão ambiental e responsabilidade social para seu crescimento. Revista da Micro e Pequena Empresa - RMPE FACCAMP, v. 1, n. 1, p. 4-23. 2007. Disponível em: <http://www.faccamp.br/ojs/index.php/RMPE/article/view/13>. Acesso em: 04.02.2016.

TINOCO, J. E. P. Balanço Social: uma abordagem socioeconômica da contabilidade, 1984. Dissertação (Mestrado) - Faculdade de Economia e Administração, Universidade de São Paulo, São Paulo.

TINOCO, J. E. P.; ROBLES, Léo T. A Contabilidade da gestão ambiental e sua dimensão para a transparência empresarial: estudo de caso de quatro empresas brasileiras com atuação global. Revista de Administração Pública. Rio de Janeiro, v. 40, n. 6, nov./dez. 2006. Disponível em: http://www.scielo.br/pdf/\%0D/rap/v40n6/08.pdf. Acesso em 20.02.2016.

VIEIRA, A. M.; RIVERA, D. P. B. A Hermenêutica no Campo Organizacional: duas possibilidades interpretativistas de pesquisa. Revista Brasileira de Gestão de Negócios, v. 14, n. 44, p. 261-273, 2012.

Recebido em: 15-8-2017

Aprovado em: 25-7-2018

Avaliado pelo sistema double blind review.

Editor: Coordenação do PPGA/UMESP

Disponível em http://mjs.metodista.br/index.php/roc 